\title{
A treatment programme for improving story-telling ability: a case study
}

Joan S. Klecan-Aker

University of Oklahoma

\section{Abstract}

The purpose of the present investigation was to measure the effects of a treatment programme on the story-telling ability of a second-grade language/learning-disabled male. Treatment was conducted twice a week for a period of 12 weeks. Results revealed an improvement in both the length and complexity of the subject's oral stories. These results are discussed relative to the role of language treatment on academic success.

\section{Introduction}

The purpose of this investigation was to measure the effectiveness of a treatment programme designed to increase a language/learningdisabled child's ability to tell a story.

One reason for studying the treatment effects of teaching narration is because the ability to tell a story or narrative may be related to learning and academic success (Milosky, 1987). For example, the production of oral narratives requires that children organize content, take into account the listener, formulate new utterances, and relate them to what has already been said. They also need to introduce referents and distinguish unambiguously among them in subsequent utterances. Oral narration is a skill that children rely on daily, both at home and school. Milosky (1987) and Klecan-Aker and Brueggeman (1991) suggest, for instance, that emphasis on oral narration as part of classroom performance continues throughout the school years. Children are often judged on their proficiency in oral expression, and their skill in this area may affect the quality of their interactions with their teachers. Language/learning-disabled children, especially, may suffer

Address for correspondence: Health Sciences Center, Department of Communication Disorders, University of Oklahoma, P.O. Box 26901, Oklahoma City, OK 73190, USA.

(C) Edward Arnold 1993 
as a result of their inability to use the language in an organized and cohesive manner. If we believe this viewpoint about the relationship between story telling and academic success, our treatment programmes need to use a multidimensional framework of language proficiency, such as narration, as it relates to academic language demands (Olsen, 1982; Tannen, 1980, 1982; Westby, 1984, 1985; Hedberg and Stoel-Gammon, 1986; Klecan-Aker and Swank, 1987; Westby, Van Dongen and Haggart, 1989; Carpenter, 1991).

A second reason for an interest in assessing the success of a treatment programme is because those involved in clinical work need to be accountable for what they choose to treat and how they choose to treat it, particularly in the area of language disabilities. Although clinical professionals have made good progress in establishing measurable objectives and documenting change, I am not certain that what they sometimes select to treat is relevant to classroom success, or even if the splinter skills that are occasionally chosen by clinicians, such as improving syntax or teaching the expression of antonyms and synonyms, carry over into academic or social interactions. Even under the best of circumstances, language/learning-disabled children often have difficulty generalizing what they have learned to other settings. It therefore becomes important either to structure treatment to include generalization or to choose targets that carry over into the classroom in natural ways. Teaching a child to organize the language in a story-telling format might do both. Not only is it possible that we may be teaching a skill that could impact academic achievement, but the very skill itself could be used in a variety of classroom activities. Regardless of what we select as a treatment programme, however, we need to document its success as well as its relevance.

\section{Method}

\section{Subject description}

$A$ is a white male aged $8 ; 8$. His mother reported a normal pregnancy and delivery, with the child being healthy at birth. Currently $A$ attends second grade in a public school. The second-grade class has been adapted to suit the needs of children with learning or language problems, but who do not qualify for special education services as determined by the school district. The class contains 12 students and two full-time teachers. Prior to this school placement, $A$ attended a 
Table 1 Standard scores of psychoeducational tests administered in 1988

\begin{tabular}{llllll}
\hline & \multicolumn{2}{c}{ WISC-R } & & \multicolumn{2}{c}{ Woodcock-Johnson } \\
Verbal & Performance & Full scale & Reading & Mathematics & $\begin{array}{l}\text { Written } \\
\text { language }\end{array}$ \\
\hline 88 & 98 & 92 & 72 & 75 & 87 \\
\hline
\end{tabular}

school for children with learning problems. He was transferred to the public school setting because, academically, he was falling further and further behind grade level.

\section{Previous testing}

In $1988 A$ was given a complete psycho-educational battery. The results of that testing can be found in Table 1. The WISC-R (Wechsler, 1974) reported a verbal score of 88 , a performance score of 98 , and a resulting full scale IQ of 92. The Woodcock-Johnson PsychoEducational Battery (Woodcock and Johnson, 1987) indicated difficulties with reading and applied problems in mathematics. Table 2 summarizes the results of the standardized language tests administered at the beginning and at the end of treatment. Testing prior to treatment revealed that receptive and expressive language skills, as measured by the Clinical Evaluation of Language Functions-Revised (CELF-R) (Semel, Wiig and Secord, 1987) and reported as ageequivalent scores were below average. The Peabody Picture Vocabulary Test-Revised (PPVT-R) (Dunn and Dunn, 1981) documented vocabulary comprehension to be in the moderately low range. The Expressive One Word Picture Vocabulary Test (EOWPVT) (Gardner, 1979) placed $A$ 's expressive vocabulary in the below-average range as well. The Woodcock Reading Mastery--Revised (Woodcock, 1987 ) indicated a difficulty with reading comprehension. The results of the standardized tests at the end of treatment will be discussed with an explanation of the effects of treatment.

Table 2 Age-equivalent scores (years/months) of standardized tests administered pre- and post-treatment

\begin{tabular}{lllll}
\hline & CELF-R $^{\mathrm{a}}$ & PPVT-R $^{\mathrm{b}}$ & EOWPVT $^{\mathrm{c}}$ & Woodcock-Reading \\
\hline Pre & $7 ; 6$ & $7 ; 3$ & $8 ; 2$ & $7 ; 3$ \\
Post & $7 ; 6$ & $7 ; 3$ & $8 ; 0$ & $7 ; 7$ \\
\hline
\end{tabular}

Notes: a CELF-R Clinical Evaluation of Language Functions-Revised.

b PPVT-R Peabody Picture Vocabulary Test-Revised.

${ }^{c}$ EOWPVT Expressive One Word Picture Vocabulary. 


\section{Procedure}

The initial step in determining specific treatment targets was the use of criterion-referenced assessment. Specifically, oral and written stories were analysed because of the possible impact telling and writing coherent narratives would have on school performance. In addition, expressing different types of stories was a goal of the second-grade curriculum.

Two oral and written stories were elicited, one week apart, and analysed as part of the measurement process. Two stories were elicited in an attempt to have a reliable measure of $A$ 's story-telling ability. Stories were subjected to a t-unit analysis (Hunt, 1970). The number of t-units, words per $\mathrm{t}$-unit, clauses per $\mathrm{t}$-unit, and words per clause were computed. Each $t$-unit was classified as a story grammar component and subsequently assigned a level of complexity (Klecan-Aker and Brueggeman, 1991). The definitions of the story-grammar components, adapted from the work of Stein and Glenn (1979), and definitions of the levels of complexity can be found in Appendix A, and the rules used in the t-unit analysis can be found in Appendix B.

The results of the criterion-referenced assessment are summarized in Table 3. Initially $A$ was telling and writing Level-2 stories. Even though standardized test measures, particularly reading and vocabulary comprehension, indicated that $A$ had problems in other areas, it was decided not to treat those deficiencies. Only the oral stories were targeted.

\section{Treatment}

Treatment consisted of two one-hour sessions each week for 12 weeks. No sessions were missed during that time period. The following procedure was used to teach $A$ about the organization and coherence of the narratives.

At the onset of treatment, general explanations of underlying

Table 3 Pre-and post-criterion-referenced assessment results

\begin{tabular}{|c|c|c|c|c|c|c|c|c|}
\hline & \multicolumn{4}{|c|}{ Pre } & \multicolumn{4}{|c|}{ Post } \\
\hline & \multicolumn{2}{|c|}{ Oral } & \multicolumn{2}{|c|}{ Written } & \multicolumn{2}{|c|}{ Oral } & \multicolumn{2}{|c|}{ Written } \\
\hline & 1 & 2 & 1 & 2 & 1 & 2 & 1 & 2 \\
\hline Number of t-units & 5 & 5 & 5 & 6 & 8 & 10 & 10 & 13 \\
\hline Words per t-unit & 8.7 & 8.6 & 7.4 & 8.0 & 8.4 & 8.0 & 7.8 & 8.2 \\
\hline Words per clause & 8.7 & 8.6 & 7.4 & 8.0 & 7.0 & 6.7 & 7.1 & 7.7 \\
\hline Clause per t-unit & 1.0 & 1.0 & 1.0 & 1.0 & 1.2 & 1.18 & 1.09 & 1.06 \\
\hline Developmental level ${ }^{a}$ & 2 & 2 & 2 & 2 & 5 & 4 & 5 & 5 \\
\hline
\end{tabular}

Note: " The termS DEVELOPMENTAL LEVEL and LEVELS OF COMPLEXITY are being used interchangeably. 
concepts of all the story-grammar components were presented to $A$ to form the base upon which the story activities were built. $A$ was told that telling stories was like baking a cake. One needed a recipe with all the ingredients listed in the right order. If one left out an ingredient or if one did not follow the steps of the recipe in the right order, the cake being baked would not turn out very well. This concept was explained in a number of different ways. It was hypothesized that, when geared to the educational level of the child, concrete explanations and examples of story-grammar components and causative relationships would facilitate later success in the treatment programme. Since $A$ was telling Level- 2 stories, the treatment began with teaching the organization of Level-3 stories.

The underlying concepts represented by story-grammar components found in Level-3 stories were explained in detail (see Appendix A). Those specific components included initiating events, attempts or actions, and consequence statements. The INITIATING EVENT was explained by saying that many stories have a problem or a plot. That is really what the story is about. Numerous examples were provided. ATtEMPTs were explained as a result of feelings. $A$ was told that when one has a certain feeling, that feeling may cause you to do something. CONSEQUENCES were explained as the result of what happens after a plan has been carried out. During this part of the programme, very little response was expected of $A$. This was considered the 'teaching' aspect of the plan. These definitions of story-grammar components were reviewed at the beginning and end of each session.

The second step in the treatment programme was to present to $A$ a series of multiple-choice activities designed around Level-3 narratives. This multiple-choice format provided a high degree of structure by asking the child to make a selection from four possible choices. $A$ was asked to choose which answer was most appropriate and tell why. An example of a Level-3 multiple-choice task is as follows: 'A boy's kite was stuck up in a tall tree. There were several things he could do. He could $(a)$ cry, $(b)$ climb up into the tree by himself, $(c)$ call his dad to get a ladder, or $(d)$ leave the kite up in the tree forever.' After $A$ selected a response we discussed why that was or was not the best answer.

When $A$ had successfully completed eight out of 10 multiple-choice Level-3 stories, the procedure was altered to a fill-in-the-blank format. With this format, $A$ was provided with the initiating event and asked to provide the best solution to the problem. An example of a Level-3 
fill-in-the-blank task is as follows: 'One day Timmy forgot his homework. What were all the things he could do? What choice is best and why?' The fill-in-the-blank format, while still providing some structure, allowed $A$ to create his own appropriate story-grammar components to further develop the story. As a result, he would become one step closer to independently creating a coherent narrative. Once eight out of 10 stories were completed successfully, the treatment programme moved to Level-4. Level-4 stories added an additional component. With $A$ that component was internal response. The same procedure was followed with Level-4 and finally Level-5 stories.

At the end of the successful completion of both the multiple choice and fill-in-the-blank story tasks at a given level, two spontaneous stories were once again elicited. The stories were elicited one week apart. The spontaneous story is the best means of determining if children are generalizing in their expressive language the story concepts that have been targeted in treatment.

\section{Results}

Pre- and post-treatment data are summarized above in Table 3. Overall, there were increases in the number of t-units, the number of clauses per t-unit and in the level of complexity. A's t-units per story ranged from 5 in the pre-test data to 8 and 10 in the post-test data. Clauses per t-unit revealed only a slight gain from 1.0 to 1.18 and 1.2 . Level of complexity showed the greatest increase. $A$ moved from spontaneously telling Level-2 stories to Level-4 and Level-5 stories. This increase in complexity involved an increase in the number of story-grammar components within the narratives. Figure 1 plots the change in levels of complexity. The standardized testing that was administered at the end of the treatment programme revealed that there was little change in receptive and expressive language scores on all measures used. Reading comprehension improved, however from an age-equivalent score of 7.3 to 7.7 (see Table 2).

\section{Discussion}

It would appear that the treatment programme designed for $A$ was successful, given the gains in his ability to tell a story. The number of 


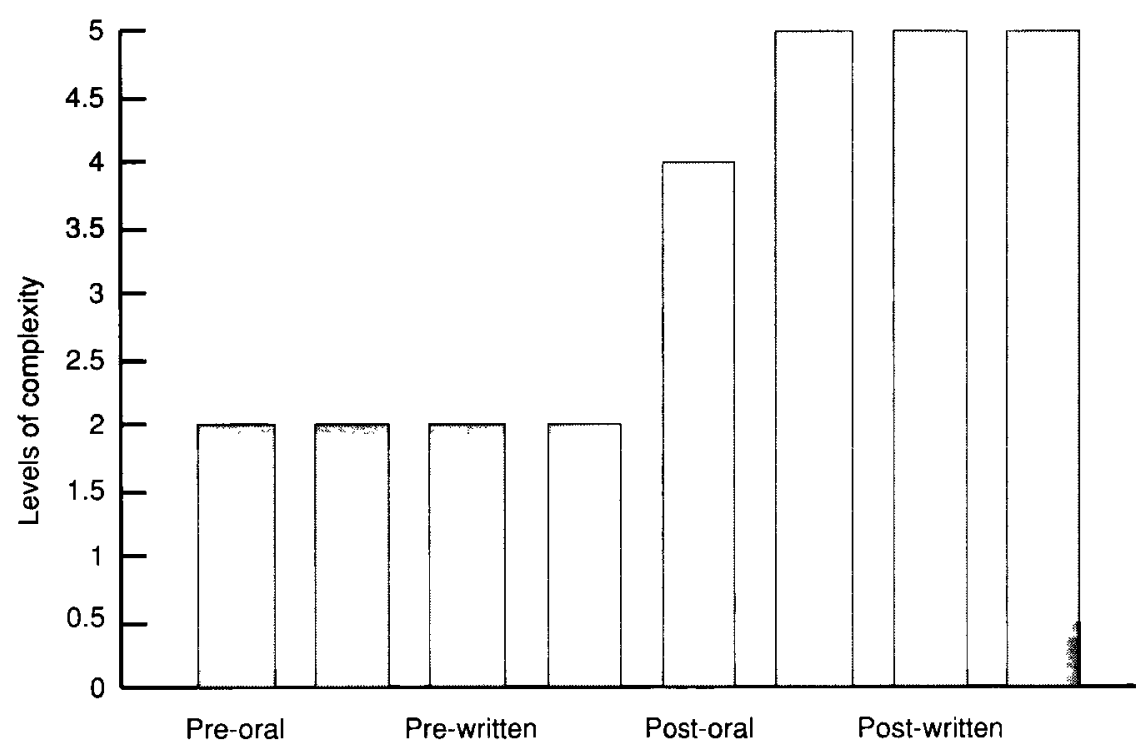

Figure 1 Pre- and post-treatment story

$\mathrm{t}$-units within the stories increased, the number of clauses per t-unit increased, and there was a substantial increase in the level of complexity of both the oral and written stories. It is interesting to note that the written stories improved as well as the oral ones, even though they were not directly targeted in treatment. That finding is not totally surprising, given the fact that the organization of stories is the same for both forms of expression. Another issue that needs to be addressed involves the fact that $A$ told stories at two different levels during post-testing. The simpler level, Level 4 , was told during the second elicitation. Upon completion of that story, $A$ commented, 'Oh no, I left out the feeling statement'. That comment at least indicates that, even if $A$ was not always spontaneously using that component in his story, he had an awareness that it should be included.

The increase in the number of $t$-units is logical as well. As children use more components in their stories, the length of the stories will naturally increase. It seems that, by using the procedure described in this case study, length and complexity of stories can be increased simultaneously.

Another issue is the pre- and post-standardized test results. These results showed very little change in $A$ 's performance, with the one small exception of Reading Comprehension. It would be easy to 
conclude that teaching a child to tell organized stories may impact reading comprehension, but that conclusion, although intriguing, is somewhat premature. Understanding how events relate to one another may indeed make it easier for a child to comprehend a test, but, at least in this case, $A$ was in a school programme that was emphasizing reading, and that, more likely, accounts for the change.

In conclusion, it appears that story telling can be taught successfully. It also appears that, as the complexity and organization of oral stories improve, the complexity and organization of written stories improve as well. When talking with the parent and classroom teachers at the end of the school year, the teachers commented on what they viewed as significant improvement in $A$ 's creativity and writing ability in storytype tasks. This viewpoint indicated two things: (1) that teaching story telling is important, and (2) that gains in that skill can impact academic success.

In a world where collaborative language treatment is becoming the norm, it seems that teaching children how to tell better stories would be an effective tool for the speech/language pathologist who will be expected to provide language treatment within a classroom setting. Future research needs to examine treatment programmes for teaching children how to tell different types of narratives, as well as the impact of language treatment over longer periods of time.

\section{References}

Carpenter, L. 1991: Distinguishing language difference from language disorder through narrative discourse analysis. Paper presented at the American Speech, Language and Hearing Association Convention, Atlanta.

Dunn, L. and Dunn, L. 1981: The Peabody Picture Vocabulary Test-Revised. Minnesota: American Guidance Service.

Gardner, M. 1979: Expressive One Word Vocabulary Test. Novata: Academic Therapy.

Hedberg, N. and Stoel-Gammon 1986: Narrative analysis: Clinical procedures. Topics in Language Disorders 7, 58-68.

Hunt, K. 1970: A syntactic maturity in school children and adults. Monographs of the Society of Research in Child Development 35 (Serial No. 134).

Klecan-Aker, J. and Brueggeman, L. 1991: The expression connection. Vero Beach: Speech Bin. 
Klecan-Aker, J. and Swank, P. 1987: The narrative styles of normal first and third grade children. Language and Speech 30, 251-262.

Milosky, L. 1987: Narratives in the classroom. Seminars in Speech and Language 8, 329-341.

Olsen, D. 1982: The language of schooling. Topics in Language Disorders 2, 1-12.

Semel, E., Wiig, E. and Secord, W. 1987: The Clinical Evaluation of Language Fundamentals-Revised. New York: The Psychological Corporation.

Stein, N. and Glenn, G. 1979: An analysis of story comprehension in elementary school children. In Freedle, R. O. editor, New directions in discourse processing, Vol. 2. Norwood: Ablex.

Tannen, D. 1980: Implications of the oral/literate continuum for cross-cultural communication. In Alatis, J. E., editor, Georgetown University Round Table on Language and Linguistics, 1980: Current Issues in Bilingual Education. Washington: Georgetown University Press.

-1982: Oral and literate strategies in spoken and written narratives, Language 58, 1-21.

Wechsler, D. 1974: Wechsler Intelligence Scale for Children-Revised. New York: The Psychological Corporation.

Westby, C. 1984: Development of narrative language abilities. In Wallach, G. and Butler, K., editors, Language learning disabilities in school-age children, Baltimore: Williams and Wilkins.

1985: Learning to talk-talking to learn: oral literate language differences. In Simon, C. S., editor, Communication skills and classroom success: therapy methodologies for language-learning disabled students. San Diego: College Hill Press.

Westby, C., Van Dongen, R. and Haggart, Z. 1989: Assessing narrative communicative competence. Seminars in Speech and Language 10, 61-75.

Woodcock, R. 1987: Woodcock Reading Mastery Tests-Revised. Circle Pines: American Guidance Service.

Woodcock, R. and Johnson, M. 1977: Woodcock-Johnson PsychoEducational Battery. Allen: DLM Teaching Resources.

(Received 12 April 1993) 


\section{Appendix A}

\section{Definitions of story-grammar components}

$\begin{array}{ll}\text { SETTING: } & \text { settings introduce the main character and tell } \\ \text { where the story takes place. } & \\ \text { INITIATING EVENT: } & \text { a statement of a problem. } \\ \text { ATTEMPT/ACTION: } & \text { an attempt to solve the problem. } \\ \text { INTERNAL RESPONSE: } & \text { thinking or feeling statements. } \\ \text { CONSEQUENCE: } & \begin{array}{l}\text { the result of the attempt or action; an out- } \\ \text { come. }\end{array} \\ \text { ENDING: } & \begin{array}{l}\text { a resolution of the problem; can also be a } \\ \text { summary statement. }\end{array}\end{array}$

Definitions of complexity levels

Level 1 No real use of story grammar components. Children are labelling or describing events, actions or objects. There is no central theme.

Level 2 No real use of story grammar components. Children are still labelling or describing, but this time their statements follow a central theme or one topic.

Level 3 These stories contain the three story-grammar components of initiating event, attempt, and consequence. Children are also beginning to use subordination.

Level 4 These stories contain the three story-grammar components found in Level 3, plus one more. The fourth component may vary from child to child.

Level 5 These stories contain the three story-grammar components found in Level 3, plus one more and an ending. If a child is using all the story-grammar components, the narrative will also be classified as a Level 5. The endings of Level-5 stories are strong and indicate a resolution to the initial problem.

Level 0 Any story that cannot be placed in one of the other categories.

\section{Appendix B}

The following rules were used for dividing the narratives of $A$ into t-units.

(1) Exact repetitions of words or phrases were not counted. 
(2) Direct quotations such as 'he said, I want to go' were considered two t-units.

(3) Unintelligible words were counted as one.

(4) If there was more than one unintelligible word per t-unit, the entire utterance was discounted.

(5) Only subject-verb contractions were counted as two words. All other contractions counted as one word.

(6) Proper and compound nouns counted as one word. 